\title{
Expression of Nucleoprotein Gene of CTN Strain Rabies Virus from China in $E$. coli with Antigenicity
}

\author{
Wangbin Cao, Ying He*, Qiumei Shi, Cairan Yang, Yanying Zhang \\ Department of Animal Science, Hebei Key Laboratory of Preventive Veterinary, Hebei Normal \\ University of Science \& Technology, Qinhuangdao, China \\ Email: *cajolehe@126.com, wangbincao@126.com, shiiqiumei@126.com, \\ ycairan@126.com, yyzhang@126.com
}

Received August 28, 2013; revised September 28, 2013; accepted October 4, 2013

Copyright (C) 2013 Wangbin Cao et al. This is an open access article distributed under the Creative Commons Attribution License, which permits unrestricted use, distribution, and reproduction in any medium, provided the original work is properly cited.

\begin{abstract}
The nucleoprotein (NP) gene of rabies CTN strain isolated from China was recombined into pMal-c2x. The antigenicity of the recombined MBP-NP fusion proteins was examined by western blotting and by enzyme linked immunosorbent assay (ELISA). The results demonstrated that the recombined protein possesses predominant antigenicity.
\end{abstract}

Keywords: Rabies Virus; Nucleoprotein; CTN Strain; Antigencity; Expression

\section{Introduction}

Rabies in humans remains a serious public health problem in many countries, where rabies virus transmission among wildlife or domestic animal populations continues to threaten humans exposed to rabic animals [1]. Dogs play an important role in rabies occurrence; human rabies transmitted by rabid dogs accounted for $83 \%$ of registered cases in China from 1980 to 1994 [2].

Rabies is a fatal viral zoonosis caused by viruses of the Lyssavirus genus of the Rhabdoviridae family. The rabies virus is a nonsegmented negative-strand RNA virus encoding five monocistronic mRNAs encoding the nucleoprotein $(\mathrm{N})$, phosphoprotein $(\mathrm{P})$, matrix protein $(\mathrm{M})$, the transmembrane glycoprotein $(\mathrm{G})$, and the viral RNAdependent RNA polymerase (L) [3,4]. Nucleoprotein forms the ribonucleoprotein which completely and tightly encapsulates the genomic and antigenomic RNA of the rabies virus. The $\mathrm{N}$ gene, which consists of 1353 nucleotides and encodes 450 amino acids, is well conserved among lyssaviruses [5]. Moreover, nucleoprotein is an important antigen protein with conserved epitopes, which can activate cell immunity in the body [6-8]. So gene products can be a feasible alternative to develop genetically engineering vaccines and diagnostic reagents.

\footnotetext{
"Corresponding author.
}

In this study, the nucleoprotein gene of a CTN strain rabies virus was expressed. This work not only provides a useful understanding of the nucleoprotein of the rabies virus, but also opens up new possibilities for the development of novel research and clinical applications. The recombinant fusion protein with antigenicity can be used for a safe, stable and easy method for detecting an antirabies antibody in dogs and it can be used to understand the rabies epizootic in wild and domestic animals.

\section{Materials and Methods}

\subsection{Plasmids, Cell and Serum Samples}

The pGEM-T/NP from CTN strain Rabies virus was stored in our lab. Bacterial cell JM109 was cultured in LB medium, and plasmids pGEM-T and pMal-c2x were purchased from Promega and NEB. Polyclonal anti-serum was obtained from the biology lab of the Institute of Lanzhou in China. The serum samples were taken from 68 domestic dogs that had been vaccinated, and 3 dogs that had no history of vaccination, based on records from the Veterinary Medicine Hospital of China Agricultural University. Standard Positive and negative serum were kindly given by the Veterinary Institute of the Military Medical Academy of Sciences. Anti-rabies serum was obtained from the Lanzhou Veterinary Research Institute Chinese Academy of Agricultural Sciences. 


\subsection{Expression of Rabies Virus $\mathbf{N}$ Gene in $E$. coli and Purification the $\mathrm{N}$ Protein}

The $\mathrm{N}$ sequences were amplified from pGEM-T/NP with two primers $\left(5^{\prime}\right.$ CTGCGAATTCACGATGGATGCCGACAAGATTGTA3' and 5'GCCACTGCAGTTATGAGTCACTCGAATATGT3'), digested with Ecol I and Pst $\mathrm{I}$, and recloned into pMal-c2x initially. The recombinant plasmids were named pMal-NP and transformed into JM109 cells, and the bacteria were grown in LB containing $0.2 \%$ glucose grown to $2 \times 10^{8}$ cells $/ \mathrm{ml}$ (OD $0.5 / \mathrm{A}$ 600). IPTG was added to a final concentration of $0.3 \mathrm{mM}$ and the cells were incubated at $37^{\circ} \mathrm{C}$ for $2 \mathrm{~h}$. Boiled bacterial lysates were analyzed by $12 \%$ sodium dodecyl sulfate-polyacrylamide gel electrophoresis (SDS-PAGE). The cell extract was isolated from a $100 \mathrm{ml}$ bacterial culture. Then the culture was quicked-chilled in ice water and the cells were harvested by centrifugation and frozen in column buffer $(20 \mathrm{mM}$ Tris-HCI, $200 \mathrm{~m} \mathrm{MNaCI}, 1$ mM EDTA, $1 \mathrm{mM}$ sodium azide and $10 \mathrm{mM} ß$-mercaptothanole) overnight at $-20^{\circ} \mathrm{C}$. The MBP fusion protein in the soluble fraction was purified using an amylose resin column in affinity chromatography and cleavaged with factor Xa following the manufacturer's instructions. The fusion protein was eluted with elution buffer (column buffer with $10 \mathrm{mM}$ maltose).

\subsection{Western Blotting}

The protein purified by affinity chromatography was separated in $12 \%$ SDS-PAGE and transferred to a PVDF membrane (Bio-rad). Blots were blocked for $1 \mathrm{~h}$ in $4 \%$ FBS in PBS (pH 7.4), then washed three times using western blot washing solution and incubated with a polyclonal house anti-serum $(1: 800)$ for $1 \mathrm{~h}$ at room temperature. Blots were then washed three times with washing buffer, and secondary rabbit anti-horse $\operatorname{IgG}(1: 10000)$ conjugated to horseradish peroxidase was added. Blots were then incubated for $1 \mathrm{~h}$ at room temperature, and then washed for 15 minutes three times with washing buffer. After this, DAB was added to produce some strips and the reaction was stopped.

\subsection{ELISA Method}

Ninety-six-well plates (Clustar) were coated with the antigen in each well and incubated overnight at $4^{\circ} \mathrm{C}$. Plates were blocked by incubating for $30 \mathrm{~min}$ at $37^{\circ} \mathrm{C}$ using 5\% glutin in PBS followed by three washings in $0.1 \%$ PBS-Tween 80 . Serum dilutions (1:50) were prepared and added to the wells and incubated for $1 \mathrm{~h}$ at room temperature followed by three more washings in $0.1 \%$ PBS-Tween 80 . Secondary antibody, goat anti-dog IgG horseradish peroxidase (1:5000) was added and the samples were incubated for $1 \mathrm{~h}$ at room temperature followed by three more washings in $0.1 \%$ PBS-Tween.
O-Phenylendiamine dihydrochloride was used to develop horseradish peroxidase-conjugated antibodies for $15 \mathrm{~min}$ at $37^{\circ} \mathrm{C}$ and stopped by adding $1 \mathrm{M} \mathrm{H}_{3} \mathrm{PO}_{4}$. Plates were read for optical density at $490 \mathrm{~nm}$ using a kinetic microplate reader.

\section{Results}

\subsection{Expression of Rabies $\mathrm{N}$ in $E$. coli and Purification of the MBP-NP Fused Protein}

The recombinant plasmid pMal-NP was checked by restriction enzyme analysis and sequencing (Figures 1 and 2), and then transformed into E. coli JM109. The JM109 cells were induced with IPTG and subjected to SDS-PAGE. The results indicated that the rabies nucleoprotein gene could be highly expressed in the competent cells of E. coli JM109 (about 25\% in total cell proteins) (Figure 3).

By using an amylose resin column in affinity chromatography, NP-MBP fusion protein was purified; the nucleoprotein was obtained by cleaving NP-MBP fusion protein with factor $\mathrm{Xa}$ and western blotting using polyclonal anti-serum of rabies identified both MBP-NP fusion protein and NP (Figures 4 and 5)

\subsection{ELISA to Determine Anti-Rabies Antibody Level in Dog Using NP-MBP Fusion Protein}

A series of indirect ELISAs were conducted to establish an ELISA method for detecting the antirabies antibody level in dogs using NP-MBP fusion protein as antigen. The recombinant protein possesses good antigenticity.

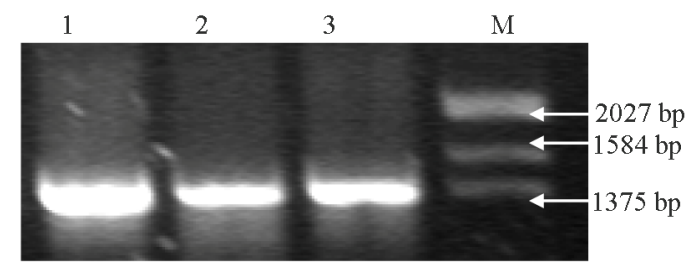

Figure 1. Identification of plasmid pMal-NP by PCR. Line 1-3: PCR product of positive; Line M: $\lambda \mathrm{DNA} / \mathrm{EcoRI}+$ Hind III marker.

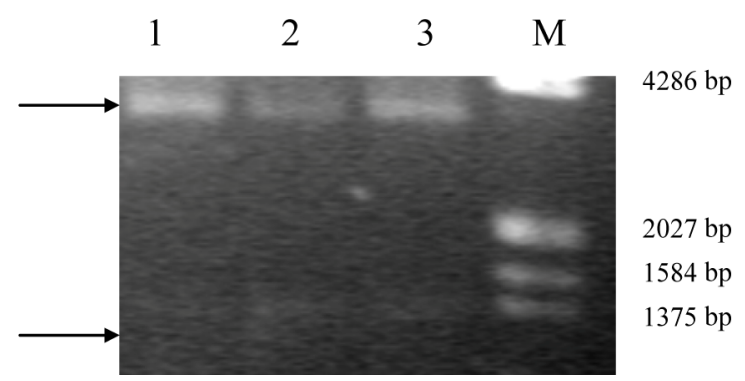

Figure 2. Identification of plasmid pMal-NP by digested by EcoRI and PstI. Line 1-3 pMal-NP digested by EcoRI and PstI; Line M: $\lambda$ DNA/EcoRI + Hind III marker. 


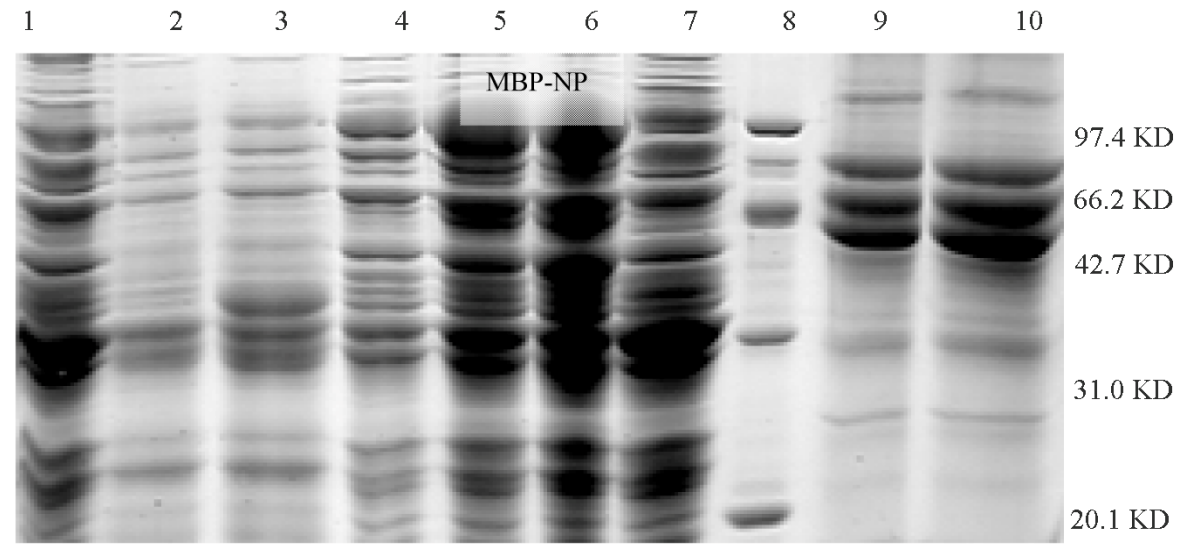

Figure 3. SDS-PAGE analysis of MBP-NP fusion protein expressed in $E$.coil; 2,3 pMal-c2x $E$. coil lysate before and after IPTG induction; 1, 9, 10 JM109 lysate before and after PTG induction; 4, 5, 6, 7 pMal-NP E. coil lysate at $1 \mathrm{~h}, 2 \mathrm{~h}, 4 \mathrm{~h}$ after or before IPTG induction 8MW marker.

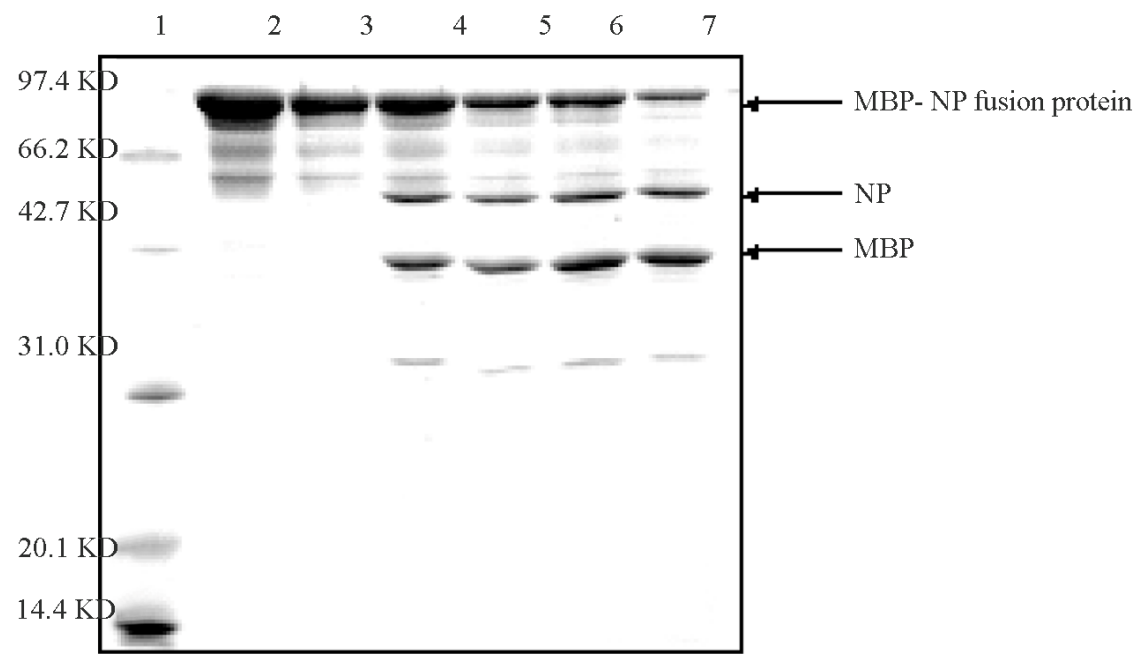

Figure 4. SDS-PAGE analysis of purified MBP_NP and MBP-NP cleavage; 1 MW marker 2 purified MBP-NP; 3, 4, 5,6, 7, 0 $h, 2$ h, 4 h, 8 h and 24 h after Factor Xa cleavage.

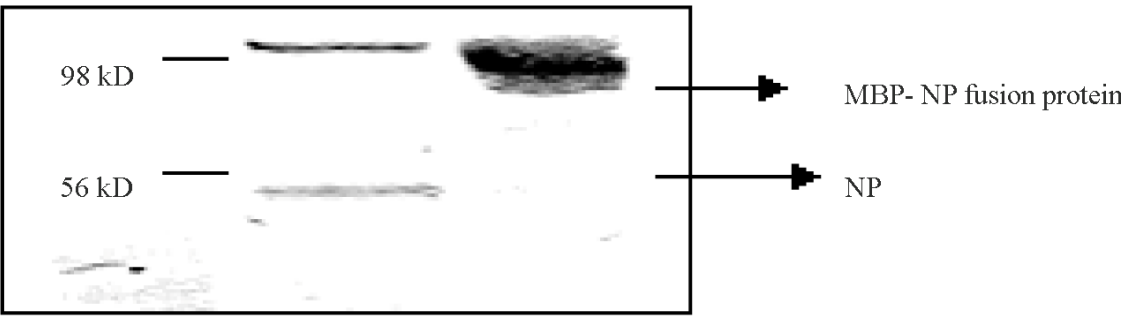

Figure 5. Western blotting analysis of purified MBP-NP fusion protein and product after factor Xa cleavage.

The best quantity of antigen coated in each well was $6 \mathrm{ug}$ MBP-NP fusion protein. Positive and negative serum testing showed that the method had high specificity. Compared to the purchased ELISA kit with rabies virion antigen, specificity of the fusion nucleoprotein was better and the sensitivity was higher (Figure 6). Testing 68 sera of vaccinated dogs and 3 sera of nonvaccinated dogs, the specificity was $100 \%$.

\section{Discussion}

Nucleoprotein is a nucleocapsid protein in the rabies virus and the major internal component of the rabies virion [3]. The $\mathrm{N}$ gene is the most conservative of the five structure genes $[9,10]$. The results of the present study confirmed this. The average conservation of the nucleotide sequence in the $\mathrm{N}$ gene and amino acid sequence among the ten fixed rabies strains is $91.2 \%$, and $96.4 \%$. 


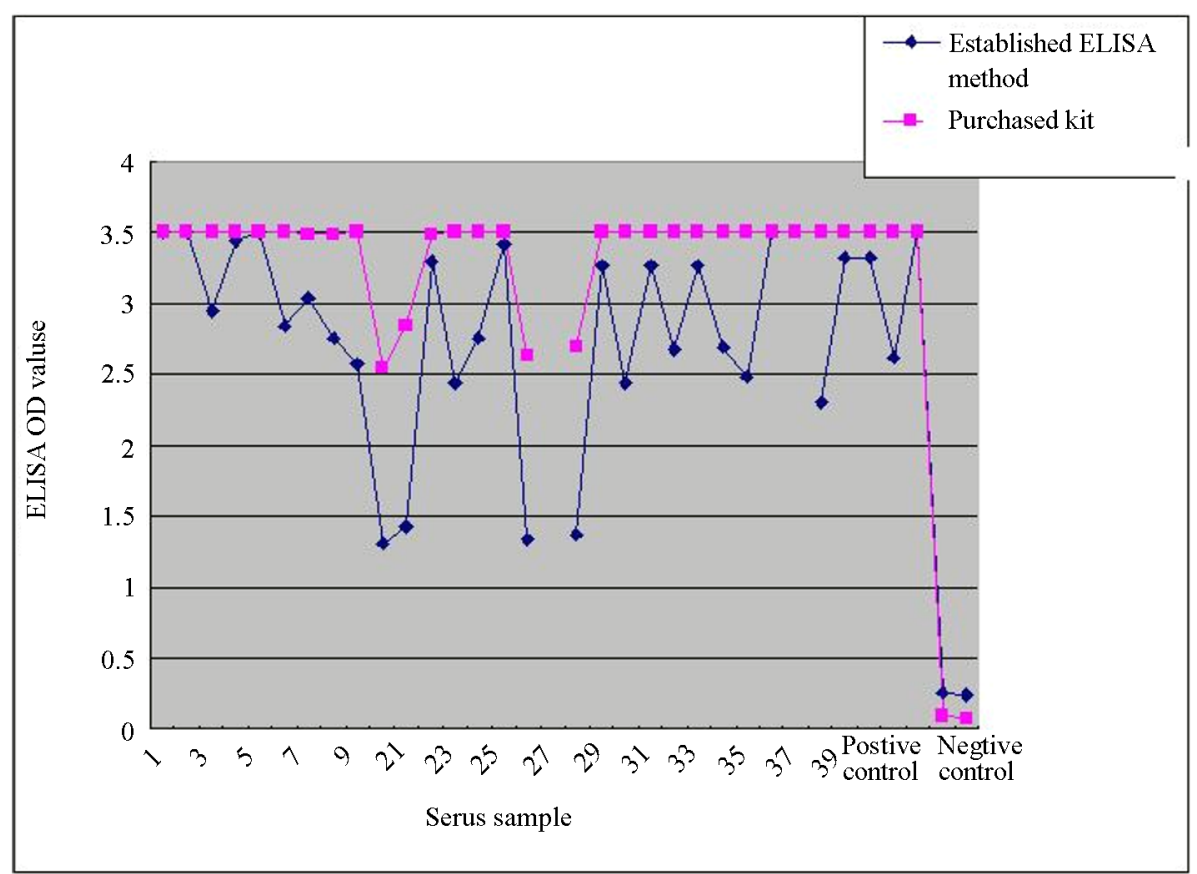

Figure 6. Comparison between the Established ELISA method with MBP-NP as coated antigen and purchased ELISA kit

The distance of different strains was exhibited in the time in which the virus was isolated. The CTN rabies strain has more similarity with the India strain. Moreover, both the $3 \mathrm{aG}$ and $5 \mathrm{aG}$ vaccine strains from China have less similarity with the CTN strain.

Flamand has shown that the N protein has group-specific antigenic determinants that are shared by all rabies viruses [6].The reports have shown that antigenic sites I and IV, and antigenic sites II and III on the NP are composed of linear- and conformation-dependent epitopes, respectively [11-13]. The amino acid sequence of antigenic site I of NP in all rabies strains is the same; but there is more variation in antigenic site IV. Residue 379 in antigenic site IV of CTN was leucine, which was differenct from the other strains, in which the residue is valine.

To futher understand the molecular properties of the $\mathrm{N}$ protein of the CTN rabies strain, a great quantity of recombinant fusion MBP-NP was produced in E. coli. As it is difficult to directly purify the $\mathrm{N}$ protein from rabies virion, recombinant $\mathrm{N}$ protein subunit was the best option. The two linear epitopes and non-glycosylation in the NP makes it possible to produce nucleoprotein with a biological function in $E$. coli. The expression quantity of $\mathrm{N}$ protein in proeukaryote cells is high, purification is easy, and MBP-NP fusion protein still exhibited good antigenticity and antigenic specificity. Therefore, the NP subunit protein expressed from the CTN rabies strain in the present study can be used as a diagnostic antigen and immunogen for the prevention and control of rabies. Also, the NP subunit protein can be an alternative to manipu- lating live viruses in diagnostic tests and vaccine production.

An enzyme linked immunosorbent assay (ELISA) has been used successfully for the qualitative assessment of rabies virus-specific antibodies in serum samples from a cohort of vaccinated dogs and cats [14] Cliquet et al. showed that data generated using this prototype ELISA indicate a strong correlation for specificity when compared to the gold standard fluorescent antibody virus neutralisation (FAVN) test. Although the ELISA has a lower sensitivity than the FAVN test, it is a useful tool for rapidly screening serum samples from vaccinated companion animals [14]. In the present study, an ELISA test using MBP-NP fusion protein as coated antigen was constructed to determine the properties of the NP in the CTN rabies strain.

His-tagged recombinant $\mathrm{N}$-protein was used as a safe and stable antigen for FELISA test, Inouse et al. [15] showed that the virus neutralization titers by rapid fluorescence focus inhibition test correlated well with the FELISA results $(r=0.616)$ and the sensitivity and specificity of the FELISA were 91.7 and $100 \%$. A $100 \%$ specificity was obtained by using sera of vaccinated and nonvaccinated dogs in our study. The safe and convenient test using MBP-NP would contribute to our understanding of the status of herd immunity among not only domestic dogs but also wild animals.

Antigenic proteins of whole virion have been used as diagnostic antigen and immunogens for the control of viral diseases. However, the whole virus proteins sometimes exhibit low specificity in diagnostic tests and im- 
mune responses. Therefore, futher efforts should be geared toward genetically engineered subunit proteins to overcome these problems.

\section{Conclusion}

The nucleoprotein (NP) gene of a CTN strain rabies virus was expressed. The antigenicity of the recombined MBP-NP fusion proteins was examined by western blotting and by enzyme linked immunosorbent assay (ELISA). An enzyme linked immunosorbent assay (ELISA) has been used successfully for the qualitative assessment of rabies virus-specific antibodies in serum samples.

\section{Acknowledgements}

The authors thank supported by Grant of Hebei Education Department (No Z2007212).

\section{REFERENCES}

[1] C. E. Rupprecht, C. A. Hanlon and T. Hemachudha, "Rabies Re-Examined," The Lancet Infectious Diseases, Vol. 2, No. 6, 2002, pp. 327-343. http://dx.doi.org/10.1016/S1473-3099(02)00287-6

[2] "Rabies," Biotech Business Week, Vol. 4, No. 12, 2004, p. 448.

[3] W. H. Wunner and J. K. Larson, "The Molecular Biology of Rabies Viruses," Reviews of infectious diseases, Vol. 10, Suppl. 4, 1988, pp. 771-784. http://dx.doi.org/10.1093/clinids/10.Supplement 4.S771

[4] W. H. Wunner, "The Chemical Composition and Molecular Structure of Rabies Viruses," In: G. M. Baer, Ed., The Natural History of Rabies. CRC Press, Boca Raton, 1991, pp. 31-67.

[5] K. K. Conzelmann, "Nonsegmented Negative-Strand RNA Viruses: Genetics and Manipulation of Viral Genomes," Annual Review of Genetics, Vol. 32, 1998, pp. 123-162. http://dx.doi.org/10.1146/annurev.genet.32.1.123

[6] A. Flamand, T. J. Wiktor and H. Koprowshi, "Use of Hybridoma Monoclonal Antibodies in the Detection of Antigenic Differences Between Rabies and Rabies-related Virus Proteins. I. The Nucleocapsid Protein," Journal of General Virology, Vol. 48, No. 1, 1980, pp. 97-104. http://dx.doi.org/10.1099/0022-1317-48-1-97

[7] H. C. Ertl, B. Dietzschold, M. Gore, L. Otvos Jr., J. K. Larson, W. H. Wunner and H. Koprowski, "Induction of Rabies Virus-Specific T-Helper Cells by Synthetic Pep- tides That Carry Dominant T-Helper Cell Epitopes of the Viral Ribonucleoprotein," Journal of Virology, Vol. 63, No. 7, 1989, pp. 2885- 2892.

[8] H. Goto, N. Minamoto, H. Ito, M. Sugiyama, T. Kinjo, K. Mannen, K. Mifune and A. Kawai, "Nucleotide Sequence of the Nucleoprotein Gene of the RC.HL Strain of Rabies Virus, a Seed Strain Used for Animal Vaccine Production in Japan," Virus Genes, Vol. 8, No. 2, 1994, pp. 91-97. http://dx.doi.org/10.1007/BF01703607

[9] A. Kawai, J. Anzai, Y. Honda, K. Morimoto, K. Takeuchi, T. Kohno, K. Wakisaka, H. Goto and N. Minamoto, "Monoclonal Antibody \#5-2-26 Recognizes the Phosphatase-Sensitive Epitope of Rabies Virus Nucleoprotein," Microbiology \& Immunology, Vol. 41, No. 1, 1997, pp. 33-42.

[10] Q. Ouyang, C. Tang, J. Zheng and J. Zhu, "Cloning and Sequencing of Nucleoprotein Gene of Chinese Rabies Virus Vaccine Strain (5aG)," Zhonghua Shi Yan He Lin Chuang Bing Du Xue Za Zhi, Vol. 11, No. 1, 1997, pp. 13-15.

[11] H. Goto, N. Minamoto, H. Ito, N. Ito, M. Sugiyama, T. Kinjo and A. Kawai, "Mapping of Epitopes and Structural Analysis of Antigenic Sites in the Nucleoprotein of Rabies Virus," Journal of General Virology, Vol. 81, No. 1, 2000, pp. 119-127.

[12] N. Minamoto, H. Tanaka and M. Hoshida, "Linear and Conformation-Dependent Antigenic Sites on the Nucleoprotein of Rabies Virus," Microbiology and Immunology, Vol. 38, No. 6, 1994, pp. 449-455.

[13] S. Inoue Y. Sato, H. Hasegawa, A. Noguchi, A. Yamada, T. Kurata and T. Iwasaki, "Cross-Reactive Antigenicity of Nucleoproteins of Lyssaviruses Recognized by a Monospecific Antirabies Virus Nucleoprotein Antiserum on Paraffin Sections of Formalin-Fixed Tissues," Pathology International, Vol. 53, No. 8, 2003, pp. 525-533. http://dx.doi.org/10.1046/j.1440-1827.2003.01511.x

[14] F. Cliquet, L. M. Mcelhinney, A. Servat, J. M. Boucher, J. P. Lowings, T. Godard, K. L. Mansfield and A. R. Fooks, "Development of a Qualitative Indirect ELISA for the Measurement of Rabies Virus-Specific Antibodies from Vaccinated Dogs and cats," Journal of Virological Methods, Vol. 117, No. 1, 2004, pp. 1-8. http://dx.doi.org/10.1016/j.jviromet.2003.12.001

[15] S. Inoue, Y. Motoi, T. Kashimura, K. Ono and A. Yamada, "Safe and Easy Monitoring of Anti-Rabies Antibody in Dogs Using His-Tagged Recombinant N-Protein," Japanese Journal of Infectious Diseases, Vol. 56, No. 4, 2003, pp. 158-160. 